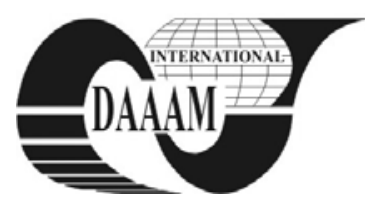

\title{
EFFECT OF MACHINING PARAMETERS ON MRR DURING WIRE ELECTRIC DISCHARGE CUTTING OF SICP/6061 AL MMC
}

\author{
SHANDILYA, P[ragya] \& JAIN, P[ramod] K[umar]
}

\begin{abstract}
This paper reports experimental investigations of the effect of machining parameters namely servo voltage (SV), pulse-on time $\left(T_{O N}\right)$, pulse-off time $\left(T_{O F F}\right)$ and wire feed rate (WF) on material removal rate (MRR) during wire electrical discharge machining (WEDC) of $\mathrm{SiC}_{p} / 6061$ Al metal matrix composite (MMC). The experiments were conducted using onefactor-at-a-time experiment strategy in which only one input parameter was varied while keeping all others input parameters constant. It was found that maximum value of MRR is obtained at lower value of voltage, higher value of pulse-on time, lower value of pulse-off time and lower value of wire feed rate.
\end{abstract}

Keywords: metal matrix composite (MMC), wire electric discharge cutting (WEDC), material removal rate (MRR)

\section{INTRODUCTION}

Concerning industrial applications, MMCs now have a proven record of accomplishment as successful hightechnology materials due to the properties such as high strength-to-weight ratio, high toughness, lower value of coefficient of thermal expansion, good wear resistance, and capability of operating at elevated temperatures (Taha, 2001; Rosso, 2006). MMCs are fabricated using several processes such as casting, forging and extrusion. However, cutting and finishing operations of MMCs are not well understood. The use of traditional machining processes to machine hard composite materials causes serious tool wear due to abrasive nature of reinforcing particles thus shortening tool life (Yan and Wang, 1993; Monaghan and Reilly, 1992). Although, nontraditional machining techniques such as water jet machining (WJM) and laser beam machining (LBM) can be used but the machining equipment is expensive, height of the workpiece is a constraint, and surface finish obtained is not good (Muller and Monaghan, 2000). On the other hand, some techniques such as electric discharge machining (EDM) and wire electric discharge machining (WEDM) are quite successful for machining of MMCs. EDM has limited applications as it can be used only for drilling purpose. WEDM which is a derived process of EDM seems to be a better choice as it conforms to easy control and can machine intricate and complex shapes. WEDM is a thermoelectrical process in which material is eroded from the workpiece by a series of discrete sparks between the workpiece and the wire electrode (tool) separated by a thin film of dielectric fluid which is continuously forced in to the machining zone to flush away the eroded particles. The movement of the wire is controlled numerically to achieve the desired three-dimensional shape and accuracy for the workpiece (as shown in Fig. 1). The setting for the various process parameters required in WEDC process play crucial role in achieving optimal performance. Lot of research work has been done on WEDM, but very few investigations have been done on WEDM of MMCs (Saha P. et al., 2009). Previous research work on WEDM focuses on one-factor-at-a time approach only on cutting speed and surface roughness; however no work has been reported on MRR. This paper presents the effect of input process parameters on MRR during WEDC of $\mathrm{SiC}_{\mathrm{p}} / 6061 \mathrm{Al} \mathrm{MMC}$.

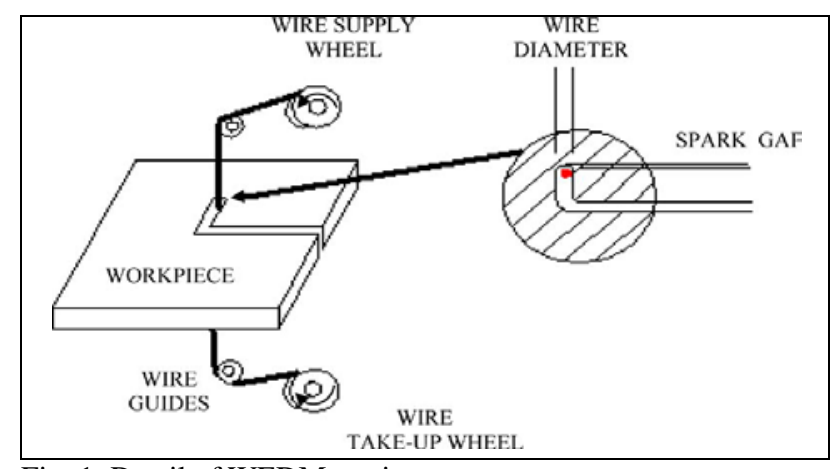

Fig. 1. Detail of WEDM cutting gap

\section{EXPERIMENTATION}

The experiments were conducted on the ECOCUT WEDM from Electronica India Pvt Ltd. 6061 aluminum based MMC, made by stir casting having $5 \%, 7.5 \%$ and $10 \%$ SiC particles (by weight) as reinforcement were used as the workpieces. The workpieces were of rectangular shape having a thickness of 6 $\mathrm{mm}$. The deionized water was used as dielectric. The dielectric temperature was kept at $20^{\circ} \mathrm{C}$. A diffused brass wire of 0.25 $\mathrm{mm}$ diameter was used as the cutting tool. The four input parameters namely servo voltage $(S V)$, pulse-on time $\left(T_{O N}\right)$, pulse-off time $\left(T_{O F F}\right)$ and wire feed rate $(W F)$ were chosen as variables to study their effect on the quality of cut in machining of $\mathrm{SiC}_{\mathrm{p}} / 6061$ aluminum MMC with MRR as response parameters. To calculate the MRR, the following equation (Nito et al., 2006) is considered:

$$
M R R=\frac{M f-M i}{\rho t}
$$

Where $M i, M f$ are masses (in gm) of the work material before and after machining respectively, $\rho$ is the density of workpiece material and $t$ is the time of machining in minutes. An electronic weighing machine with an accuracy of $0.1 \mathrm{mg}$ is used to weight the material.

\section{EXPERIMENTAL RESULTS AND ANALYSIS}

Fig. 2(a) shows the effect of voltage on the MRR indicating that as the MRR decreases continuously with increase in the voltage for all three MMCs and that at any value of the voltage, the MRR is maximum for the MMC with $5 \% \mathrm{SiC}_{\mathrm{p}}$. Fig. 2(b) depicts the variation of the MRR with the pulse-on time indicating that the MRR increases continuously with increase in the pulse-on time for all three percentage of $\mathrm{SiC}_{\mathrm{p}}$ and its value being highest for the MMC with $5 \% \mathrm{SiC}_{\mathrm{p}}$ at any value of the pulse-on time. Fig. 2(c) shows the effect of pulse-off time on the MRR depicting that the MRR continuously decreases 


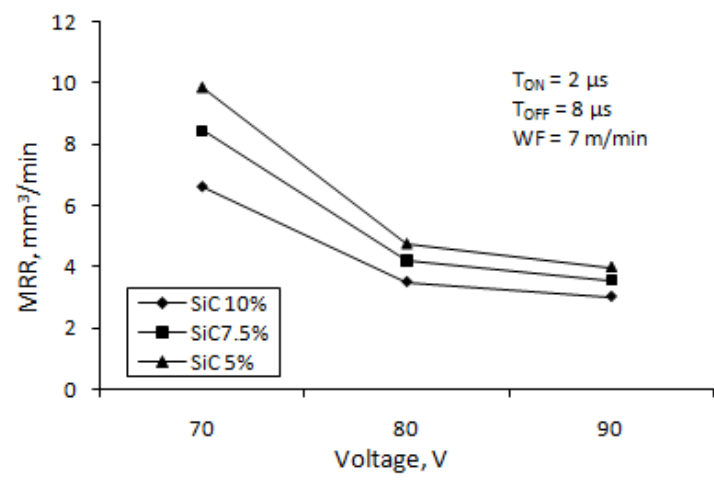

(a)

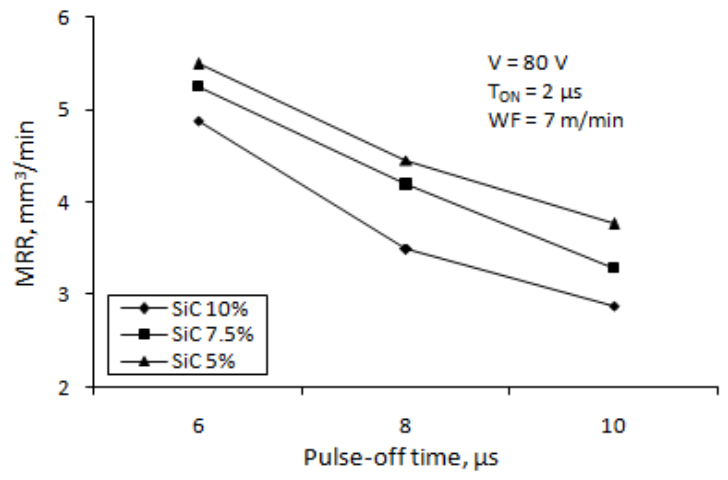

(c)

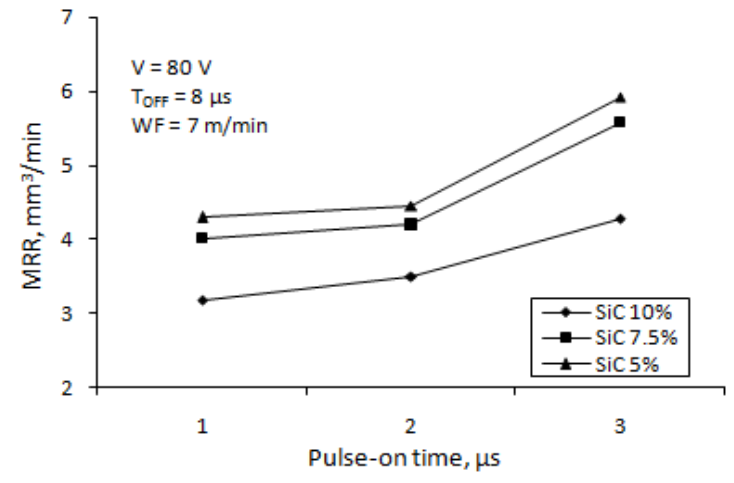

(b)

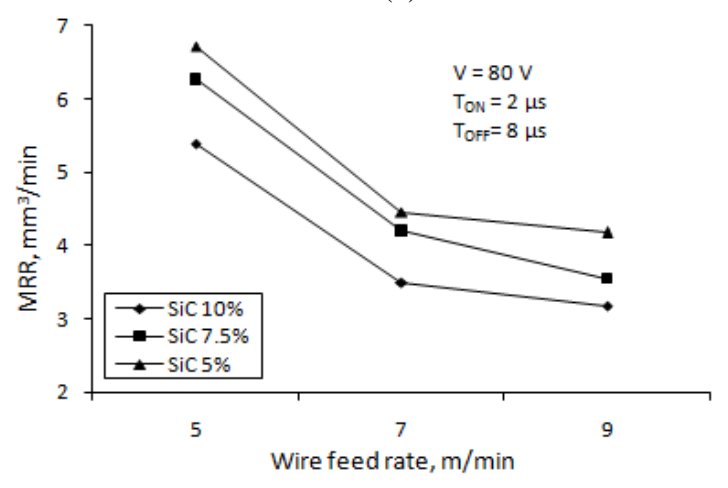

(d)

Fig. 2. Effect of (a) servo voltage; (b) pulse-on time; (c) pulse-off time; (d) wire feed rate on MRR

with increase in pulse-off time and value of MRR is maximum for $5 \% \mathrm{SiC}_{\mathrm{p}}$. Fig. 2(d) shows the effect of wire feed rate on the MRR. From this graph it is evident that the MRR decreases with increase in the wire feed rate for all the three percentage of $\mathrm{SiC}$ particles. It is also clear from these graphs that MRR is maximum for the MMC with 5\% $\mathrm{SiC}$ particles, which shows that as the percentage of $\mathrm{SiC}$ particles increases MRR decreases.

\section{CONCLUSIONS}

From the experimental investigations on WEDC of 6061 aluminum alloy based MMC reinforced with three different percentage of the $\mathrm{SiC}$ particles it can be conclude that to achieve higher value of the MRR, lower value of voltage, higher value of pulse-on time, lower value of pulse-off time and lower value of wire feed rate should be used. At any given value of any of the four parameters the MMC with $5 \% \mathrm{SiC}_{\mathrm{p}}$ gives the highest value of the MRR among the three \% of the $\mathrm{SiC}$ particles considered in this work. The present work is focused on the WEDC of $\mathrm{SiC}_{\mathrm{p}} / 6061 \mathrm{Al} \mathrm{MMCs}$ upto $10 \% \mathrm{SiC}$ particles. In future the study can be extended using different work material, process parameters and performance measures. Levels of process parameters like wire tension, table feed rate etc. that have been fixed during this study may be varied for further investigations to determine the machinability of MMCs during WEDC process.

\section{REFERENCES}

Monaghan, J.M. and Reilly, P.O. (1992). The drilling of an $\mathrm{Al} / \mathrm{SiC}$ Metal matrix composite, Journal of Materials Processing Technology, Vol., 33 (4), pp.469-480

Muller, F. and Monaghan, J. (2000). Non-conventional machining of particle reinforced metal matrix composite, International Journal of Machine Tools and Manufacture, Vol.40, pp.1351-1366

Neto, J.C.S.; Silva, E.M. and Silva, M.B. (2006). Intervening variables in electrochemical machining. Journal of Materials Processing Technology, Vol.179 (1-3), pp.92-96

Rosso, M. (2006). Ceramic and metal matrix composites: routes and properties, Journal of composites: routes and properties, Journal of Materials Processing Technology, Vol.175, pp.364-375

Saha P.; Tarafdar D.; Pal S.K.; Srivastava A.K. \& Das K. (2009). Modeling of wire electro-discharge machining of $\mathrm{TiC} / \mathrm{Fe}$ in situ metal matrix composite using normalized RBFN with enhanced K-means clustering technique, International Journal of Advanced Manufacturing Technology, Vol.43, pp.107-116

Taha, M.A. (2001). Practicalization of cast metal matrix composites (MMCs), Mater Des, Vol. 22, pp. 431-441.

Yan, B.H. \& Wang, C.C. (1993). Machinability of SiC particle reinforced aluminum alloy composite material, Journal of Japan Institute Light Metals, Vol., 43 (4), pp. 187-192 